\title{
A Study of the Relationship between L2 Proficiency and Pragmatic Transfer in the Speech Act of Criticism
}

\author{
Deguang Zhu \\ North China Institute of Science and Technology \\ College of Foreign Languages \\ Yanjiao, Beijing East \\ China
}

\begin{abstract}
The relationship between $L 2$ proficiency and pragmatic transfer has been investigated by a few researchers, but without consistent results: some finding a positive relationship, some finding a negative one, while others finding no relationship. The present study is conducted to explore the relationship between L2 proficiency and Chinese English learners' pragmatic transfer in the speech act of criticism at both levels of production and perception. With a Discourse Completion Task (DCT) and a contextual appropriateness assessment questionnaire as the instruments designed to collect the research data at both levels of production and perception, and with Independent-Sample TTest and the Degree of Discrepancy in use frequency or contextual appropriateness assessment as the measuring instrument, based on analysis of the data provided by 54 native Chinese speakers, 30 native American English speakers, 30 high proficiency Chinese English learners, 31 intermediate proficiency Chinese English learners and 50 low proficiency Chinese English learners, four types of relationship between L2 proficiency and pragmatic transfer at both levels of production and perception are discovered - straight ascending type, straight descending type, $U$ type and inverted $U$ type, and in general, the degree of pragmatic transfer decreases as L2 proficiency increases. It is hoped that the findings of the study may provide some references for further studies of pragmatic transfer and its relationship with L2 proficiency.
\end{abstract}

Keywords: pragmatic transfer; the speech act of criticism; production; perception; L2 proficiency; the Degree of Discrepancy

\section{Research Questions and Motivation}

In the study of pragmatic transfer, there are still some questions in dispute. For instance, learners' target language proficiency is supposed to be one of the factors affecting pragmatic transfer, but no agreement is reached on the influence - some studies finding a positive relationship between linguistic proficiency and pragmatic transfer, some discovering a negative one, and others finding no relationship between them. In order to find the answer to the above disputable question, the present study explores the relationship between L2 proficiency and pragmatic transfer in the speech act of criticism at both levels of production and perception. The findings of the present research may verify the effectiveness of the research instruments, methods and measuring instruments, and provide some references for further studies of pragmatic transfer and its relationship with L2 proficiency. Theoretically, the present study makes some contributions to interlanguage pragmatics, and in practice, it could be applied to the teaching of pragmatic competence in the foreign language classroom.

The present study is designed to test how pragmatic transfer is related to learners' L2 proficiency. The following two questions are explored in the study:

1) What is the relationship between L2 proficiency and pragmatic transfer in the speech act of criticism at the level of production?

2) What is the relationship between L2 proficiency and pragmatic transfer in the speech act of criticism at the level of perception?

\section{Introduction to Key Concepts in the Present Study}

\subsection{Pragmatic Transfer}


Kasper (1992: 207) views pragmatic transfer in interlanguage pragmatics as 'the influence exerted by learners' pragmatic knowledge of languages and cultures other than L2 on their comprehension, production and learning of L2 pragmatic information." And he categorizes learners' pragmatic transfer into two types - pragmalinguistic transfer and sociopragmatic transfer, two terms deriving from Leech's classification of pragmatics into pragmalinguistics and sociopragmatics. A pragmalinguistic transfer is the influence of the learner's knowledge about the illocutionary force or politeness value assigned to particular linguistic form-functions in NL, which, when mapped by learners into the perception and production of a similar situation in TL, sounds different to native speakers. In Kasper's words, it is “the process whereby the illocutionary force or politeness value assigned to a particular linguistic material in NL influences learners' perception and production of form-function mappings in TL" (1992: 209). A sociopragmatic transfer is a process "operative when the social perceptions underlying language users' interpretation and performance of linguistic action in TL are influenced by their assessment of subjectively equivalent NL contexts" (Kasper, 1992: 209).

Pragmatic transfer can also be divided into positive transfer and negative transfer. Positive transfer can be defined as "the projection of first language-based sociopragmatic and pragmalinguistic knowledge where such projections result in perceptions and behaviors consistent with those of second language users" (Maeshiba et al., 1996: 155). Negative transfer is defined as "the projection of first language-based sociopragmatic and pragmalinguistic knowledge onto second language contexts where such projections result in perceptions and behaviors different from those of second language users" (ibid, 155).

Lu Jiawei (2010) classifies pragmatic transfer into two types - distinctive pragmatic transfer and indistinctive pragmatic transfer according to the notion of degree of discrepancy which refers to the difference in the use frequency of some semantic formula or modifier between two groups of participants, and is calculated by subtracting the small percentage from the large percentage and then being divided by the large percentage. In statistics, the first quartile (25\%) is often taken as the cut-point. That is, if the degree of discrepancy in the use of a specific semantic formula or modifier between two groups of participants is less than $25 \%$, it is presumed that there is little differences between them in their use of the semantic formula or modifier, that the degree of discrepancy is termed as indistinctive degree of discrepancy, and that the pragmatic transfer with the degree of discrepancy less than $25 \%$ is labeled as indistinctive pragmatic transfer; if the degree of discrepancy is greater than $25 \%$, it is presumed that the difference is great and significant, that the degree of discrepancy is termed as distinctive degree of discrepancy, and that the pragmatic transfer with the degree of discrepancy larger than 25\% is labeled as distinctive pragmatic transfer.

According to the degree of pragmatic transfer, Lu Jiawei (2010) further classifies distinctive pragmatic transfer into pragmatic over-transfer, apparent pragmatic transfer, unapparent pragmatic transfer and pragmatic undertransfer. This classification of pragmatic transfer provides the very basic and critical concepts for the present study.

\subsection{Pragmatic Production}

Pragmatic production refers to the participants' use of appropriate pragmatic strategies and their semantic formulas and modifiers to perform a certain speech act in a specific context. It is one of the important components of pragmatic competence, reflecting the participants' ability to use appropriate linguistic forms to express their ideas successfully. It is based on identification of the context and understanding of the hearer's real intention, as well as the natural development of correct contextual identification and understanding of the hearer's intention.

\subsection{Pragmatic Perception}

Pragmatic perception in the present study refers to the participants' assessment as to how appropriate a strategy is for a given context. It is operationally defined as the participants' ratings regarding the appropriateness of the strategies used in given contexts. The underlying assumption is that when a strategy is placed in a specific context, the participants' ratings of its contextual appropriateness are reflections of their pragmatic knowledge of contextualized form-force mapping relationship.

\subsection{Contextual Appropriateness}

S. Takahashi (1996) thinks that contextual appropriateness indicates how appropriate a speech act strategy is when placed in a particular context, or to what extend a speech act strategy fulfills its intended communicative and/or interpersonal function when the context of communication is taken into consideration. 
If a strategy (in the form of an utterance) is contextually appropriate, it should be able to convey what the speaker means, or to convey the intended illocutionary force and degree of politeness (or impoliteness) to the listener. To reach this goal, the utterance issued should be in keeping with pragmatic rules or norms functioning in the specific context.

\subsection{The Speech Act of Criticism}

The present study adopts Wierzbicka's (1987, quoted form Nguyen, 2005: 7) definition of the speech act of criticism as "an illocutionary act whose illocutionary point is to give negative evaluation on the hearer's $(H)$ actions, choice, words, and products for which he or she may be held responsible. This act is performed in hope of influencing H's future actions for the better for his or her own benefit as viewed by the speaker (S), or to communicate S's dissatisfaction/discontent with or dislike regarding what $\mathrm{H}$ has done but without implying that what $\mathrm{H}$ has done has undesirable consequences for S."

\subsection{Criticism Realization Strategies, Semantic Formulas, and Modifiers}

In the present study, criticism realization strategies are defined as the pragmalinguistic conventions of usage by which criticisms are realized. Conventions of usage in the sense used by Clark (1979) are further made up of two other kinds of pragmalinguistic conventions, namely, conventions of means and conventions of forms. The former refers to the semantic devices (or semantic formulas) by which a speech act is performed. The latter involves the exact wordings used. And so criticism semantic formulas are semantic structures that have acquired an illocutionary force representing criticisms (Clark, 1979: 430). For example, a criticism can be realized by means of different semantic formulas, from a direct strategy of "statement of the problem or wrongdoing" to an indirect strategy of "suggestion for change or repair". A semantic formula can be realized by means of different wordings. For example, a"suggestion for change" can be realized as "You should try to see the beauty and value of life", "Why don't you see the beauty and value of life?" or "A smart way to deal with the problem is to see the beauty and value of life", and so on.

Modifiers are linguistic devices employed to help reduce the offence of a face-threatening act, such as sweetener a compliment paid to the hearer either before or after a criticism to compensate for the offensive act, or hedges of all kinds to reduce the degree of severity of a criticism like "sort of", "kind of", and so on.

A criticism can be realized by either direct or indirect strategies. Following Blum-Kulka's (1987) study of the indirectness of "request", the directness level of a criticism is determined by the degree of illocutionary transparency, and thus the amount of effort needed to interpret the illocutionary point of the criticism. That is, "the more indirect the mode of realization, the higher will be the interpretive demands" (Blum-Kulka, 1987: 133). The present study, following Nguyen's (2005) classification of the direct and indirect criticism strategies and modifiers, and driven by the collected data, also categorizes the criticism strategies into direct strategies and indirect strategies, and divides the modifiers into internal modifiers and external modifiers.

The direct criticism strategies found by the writer in a research are Negative evaluation, Stopping, Disagreement (Disapproval), Identification of problem, Question for blaming, Statement of consequences, and the indirect criticism strategies are Inquiry for causes, Request (demand) for change, Advice about (suggestion for) change, Preaching (indicating standard), Reminding (hint), Presupposing, Offer help, Irony (satire). The external modifiers discovered are Steers, Addressing, Phatic expressions (greetings), Sweeteners, Disarmers, Grounders, and the internal modifiers are Interrogative, Modal, Hedges, Understaters, Subjectivizers, Consultative, Cajolers, Appealers, Terms of respect.

\section{Pragmatic Transfer Discovered in the Speech Act of Criticism}

To collect the research data at the level of production, a Discourse Completion Task (DCT) is designed with Blum-kulka (1982) and other researchers' DCTs as references, and with Clark (1979), Tracy, et al. (1987), Wierzbicka (1987), Thi Thuy Minh Nguyen (2005), Hoang Thi Xuan Hoa (2007) and some others' studies of criticism as basis. To collect the research data at the level of perception, a contextual appropriateness assessment questionnaire is designed on the basis of the DCT and the data collected. The participants involved in the study include 54 native Chinese speakers (Abbreviated as NCS) from the fields of education, health, government agencies, factories, businesses, etc. in Langfang City, Hebei Province, 30 native American English speakers (Abbreviated as NAES) from the fields of education, businesses, government offices, etc., 30 high proficiency Chinese English learners (Abbreviated as HCEL) who are English teachers with the degree of Master of Arts in 
North China Institute of Science and Technology (NCIST), 31 intermediate proficiency Chinese English learners (Abbreviated as ICEL) who are sophomores of English majorsin NCIST and 50 low proficiency Chinese English learners (Abbreviated as LCEL) who are first-year students in No. 2 Senior Middle School of Sanhe City.

Independent-Sample $\mathrm{T}$ Test and the Degree of Discrepancy in use frequency or contextual appropriateness assessment are used as the measuring instruments.

By means of Independent-Sample T Test, the differences and similarities are examined in the criticisms produced by native Chinese speakers and native American English speakers. By making analysis of the degree of discrepancy in the use frequency of the semantic formulas or modifiers used in the criticisms by native Chinese speakers, native American English speakers and Chinese English learners, pragmatic transfer is discovered in some of the semantic formulas or modifiers produced by Chinese English learners. By analyzing the degree of discrepancy in the means of contextual appropriateness assessment of the criticisms produced by native Chinese speakers and native American English speakers, pragmatic transfer is also discovered in some of the semantic formulas and modifiers when Chinese English learners perceive the speech acts of criticism produced by native Chinese speakers and native American English speakers.

It is discovered:

1) Analysis of the degree of discrepancy in use frequency shows that pragmatic transfer occurs at the level of production: in such semantic formulas and modifiers produced by HCEL as "Negative evaluation", "Stopping", "Inquiry for causes", "Phatic expressions (greetings)" and "Grounders" which belong to apparent pragmatic transfer, and "Identification of problem", "Question for blaming", "Offer help" and "Irony (satire)" which belong to unapparent pragmatic transfer; in such semantic formulas and modifiers produced by ICEL as "Identification of problem", "Stopping", "Reminding (hint)", "Phatic expressions (greetings)" and "Understaters" which belong to apparent pragmatic transfer, and "Inquiry for causes", "Question for blaming", "Offer help", "Irony (satire)", "Hedges" and "Appealers"which belong to unapparent pragmatic transfer; in such semantic formulas and modifiers produced by LCEL as "Identification of problem", "Statement of consequences", "Reminding (hint)", "Irony (satire)", "Phatic expressions (greetings)" which belong to apparent pragmatic transfer, and "Negative evaluation", "Inquiry for causes", "Question for blaming", "Offer help", and "Hedges" which belong to unapparent pragmatic transfer.

2) At the level of perception, analysis of the Degree of Discrepancy in contextual appropriateness assessment shows that: apparent pragmatic transfer occurs in 3 of the criticisms by NAES and 1 of the criticisms by NCS, and unapparent pragmatic transfer occurs in 3 of the criticisms by NAES and 7 of the criticisms by NCS when HCEL perceive their contextual appropriateness; apparent pragmatic transfer occurs in 4 of the criticisms by NAES and 3 of the criticisms by NCS, and unapparent pragmatic transfer occurs in 4 of the criticisms by NAES and 2 of the criticisms by NCS when ICEL perceive their contextual appropriateness; and apparent pragmatic transfer occurs in 3 of the criticisms by NAES and 3 of the criticisms by NCS, and unapparent pragmatic transfer occurs in 7 of the criticisms by NAES and 6 of the criticisms by NCS when LCEL perceive their contextual appropriateness.

3) Pragmatic transfer occurs in the use frequency of the semantic formulas and modifiers - "Negative evaluation", "Identification of problem", "Grounders" and "Cajolers" - in the speech acts of criticism produced by HCEL and in their contextual appropriateness assessment of the speech acts of criticism containing the abovementioned semantic formulas and modifiers by NAES; pragmatic transfer occurs in the use frequency of the semantic formulas and modifiers - "Negative evaluation", "Identification of problem", "Statement of consequences", "Grounders", "Hedges" and "Cajolers" - in the speech acts of criticism produced by ICEL and in their contextual appropriateness assessment of the speech acts of criticism containing the above-mentioned semantic formulas and modifiers by NAES; and pragmatic transfer occurs in the use frequency of the semantic formulas and modifiers - "Negative evaluation", "Identification of problem", "Inquiry for causes", "Offer help", "Addressing", "Hedges" and "Cajolers" - in the speech acts of criticism produced by LCEL and in their contextual appropriateness assessment of the speech acts of criticism containing the above-mentioned semantic formulas and modifiers by NAES.

\section{Study of the Relationship between L2 Proficiency and Pragmatic Transfer in Production of Criticisms}




\subsection{The Judging Criteria of the Relationship between L2 Proficiency and Pragmatic Transfer at the Level of Production}

The present study adopts Lu Jiawei's (2010) judging criteria of the relationship between L2 proficiency and pragmatic transfer as follows:

Under the condition of the occurrence of distinctive pragmatic transfer in the Chinese English learners' production of criticisms, if NCS display a greater count of a specific semantic formula or modifier than NAES and the lower proficiency Chinese English learners also display a greater count of the same semantic formula or modifier than the higher proficiency Chinese English learners, or if NCS display a less count of a specific semantic formula or modifier than NAES and the lower proficiency Chinese English learners also display a less count of the same semantic formula or modifier than the higher proficiency Chinese English learners, a negative co-relationship between L2 proficiency and pragmatic transfer is confirmed. That is, as the learners' linguistic proficiency increases, the degree of pragmatic transfer decreases.

Under the condition of the occurrence of distinctive pragmatic transfer in the Chinese English learners' production of criticisms, if NCS display a greater count of a specific semantic formula or modifier than NAES while the lower proficiency Chinese English learners display a less count of the same semantic formula or modifier than the higher proficiency Chinese English learners, or if NCS display a less count of a specific semantic formula or modifier than NAES while the lower proficiency Chinese English learners display a greater count of the same semantic formula or modifier than the higher proficiency Chinese English learners, a positive co-relationship between L2 proficiency and pragmatic transfer is confirmed. That is, as the learners' linguistic proficiency increases, the degree of pragmatic transfer also increases. The relationship between L2 proficiency and pragmatic transfer and the judging criteria are shown in the table below.

Table 1 The relationship between L2 proficiency and pragmatic transfer and the judging criteria at the level of production

\begin{tabular}{|l|l|}
\hline Relationship & The judging criteria \\
\hline Positive relationship & $\begin{array}{l}\mathrm{f}(\mathrm{c})>\mathrm{f}(\mathrm{a}), \mathrm{f}(\mathrm{lcl})<\mathrm{f}(\mathrm{hcl}) \\
\text { or } \mathrm{f}(\mathrm{c})<\mathrm{f}(\mathrm{a}), \mathrm{f}(\mathrm{lcl})>\mathrm{f}(\mathrm{hcl})\end{array}$ \\
\hline Negative relationship & $\begin{array}{l}\mathrm{f}(\mathrm{c})>\mathrm{f}(\mathrm{a}), \mathrm{f}(\mathrm{lcl})>\mathrm{f}(\mathrm{hcl}) \\
\text { or } \mathrm{f}(\mathrm{c})<\mathrm{f}(\mathrm{a}), \mathrm{f}(\mathrm{lcl})<\mathrm{f}(\mathrm{hcl})\end{array}$ \\
\hline
\end{tabular}

Note : $f(c)$ refers to the native Chinese speakers' use frequency of a certain semantic formula or modifier; $f(a)$ refers to the native American English speakers' use frequency of a certain semantic formula or modifier; $\mathrm{f}(\mathrm{lcl})$ refers to the lower proficiency Chinese English learners' use frequency of a certain semantic formula or modifier; $\mathrm{f}(\mathrm{hcl})$ refers to the higher proficiency Chinese English learners' use frequency of a certain semantic formula or modifier.

\subsection{The Influence of L2 Proficiency on Pragmatic Transfer in Production of Criticisms}

Based on the judging criteria about the relationship between L2 proficiency and pragmatic transfer, it is found that L2 proficiency does influence pragmatic transfer, the degree of influence being different in different semantic formulas or modifiers. In general, four types of relationship are discovered: 1) straight ascending type, namely, type of positive relationship (the degree of pragmatic transfer increases as the learners' linguistic proficiency increases); 2) straight descending type, that is, type of negative relationship (the degree of pragmatic transfer decreases as the learners' linguistic proficiency increases); 3) U type (in the early stage from LCEL to ICEL, the degree of pragmatic transfer decreases as the learners' linguistic proficiency increases, but the degree of pragmatic transfer increases as the learners' linguistic proficiency continues to increase from ICEL to HCEL); and 4) inverted U type (in the early stage from LCEL to ICEL, the degree of pragmatic transfer increases as the learners' linguistic proficiency increases, but the degree of pragmatic transfer decreases as the learners' linguistic proficiency continues to increase from ICEL to HCEL).

In 9 semantic formulas where pragmatic transfer occurs, the straight ascending type appears in "Stopping", the straight descending type in "Identificationof problem", the U type in "Negative evaluation", "Statement of consequences" and "Irony (satire)", and the inverted U type in "Question for blaming", "Inquiry for causes", "Reminding (hint)" and "Offer help". In 5 modifiers where pragmatic transfer occurs, the straight ascending type appears in "Grounders", the straight descending type in "Phatic expressions (greetings)" and "Hedges", and the inverted U type in "Understaters" and "Appealers". 
When the semantic formulas and modifiers where pragmatic transfer occurs are observed together, the inverted $\mathrm{U}$ type appears in 6 of them, and the straight descending type appears in 3 of them. It is 9 when the two types are added up, which takes around $64 \%$ of all the 4 types of relationship. Therefore, in general, it follows that the degree of pragmatic transfer decreases as L2 proficiency increases, and the relationship is negative.

Table 2 Types of relationship between L2 proficiency and pragmatic transfer in production of criticism

\begin{tabular}{|l|l|l|l|l|}
\hline Types of relationship & $\begin{array}{l}\text { Straight } \\
\text { ascending }\end{array}$ & $\begin{array}{l}\text { Straight } \\
\text { descending }\end{array}$ & U & Inverted U \\
\hline $\begin{array}{l}\text { Formulas of direct criticism } \\
\text { strategies }\end{array}$ & Stopping & $\begin{array}{l}\text { Identification of } \\
\text { problem }\end{array}$ & $\begin{array}{l}\text { Negative } \\
\text { evaluation, } \\
\text { Statement of } \\
\text { consequences }\end{array}$ & $\begin{array}{l}\text { Question for } \\
\text { blaming }\end{array}$ \\
\hline $\begin{array}{l}\text { Formulas of indirect criticism } \\
\text { strategies }\end{array}$ & Irony (satire) & $\begin{array}{l}\text { Inquiry for } \\
\text { causes, } \\
\text { Reminding, } \\
\text { Offer help }\end{array}$ \\
\hline External modifiers & Grounders & $\begin{array}{l}\text { Phatic } \\
\text { expressions }\end{array}$ & & \\
\hline Internal modifiers & & Hedges & & $\begin{array}{l}\text { Understaters, } \\
\text { Appealers }\end{array}$ \\
\hline
\end{tabular}

\section{Study of the Relationship between L2 Proficiency and Pragmatic Transfer in Perception of Criticisms 5.1 The Judging Criteria of the Relationship between L2 Proficiency and Pragmatic Transfer at the Level of Perception}

The Degree of Discrepancy in contextual appropriateness assessment is the parameter that distinguishes whether pragmatic transfer occurs or not. It is found that the average of NAES' contextual appropriateness assessment on their speech acts of criticism is higher than that of NCS' contextual appropriateness assessment on the speech acts of criticism produced by NAES. In this case, if the average of the lower proficiency Chinese English learners' contextual appropriateness assessment on NAES' speech acts of criticism is smaller than that of the higher proficiency Chinese English learners', which means that pragmatic transfer decreases when L2 learners' linguistic proficiency increases, the relationship between L2 proficiency and pragmatic transfer is negative; if the average of the lower proficiency Chinese English learners' contextual appropriateness assessment on NAES' speech acts of criticism is bigger than that of the higher proficiency Chinese English learners', which means that pragmatic transfer increases with the improvement of L2 learners' linguistic proficiency, the relationship between L2 proficiency and pragmatic transfer is positive. The relationship between L2 proficiency and pragmatic transfer and the judging criteria at the level of perception is shown in the table below.

Table 3 The relationship between L2 proficiency and pragmatic transfer and the judging criteria at the level of perception

\begin{tabular}{|l|l|}
\hline Relationship & The judging criteria \\
\hline $\begin{array}{l}\text { Positive } \\
\text { relationship }\end{array}$ & When $\mathrm{m}(\mathrm{c})<\mathrm{m}(\mathrm{a}), \mathrm{m}(\mathrm{lcl})>\mathrm{m}(\mathrm{hcl})$ \\
\hline $\begin{array}{l}\text { Negative } \\
\text { relationship }\end{array}$ & When $\mathrm{m}(\mathrm{c})<\mathrm{m}(\mathrm{a}), \mathrm{m}(\mathrm{lcl})<\mathrm{m}(\mathrm{hcl})$ \\
\hline
\end{tabular}

Note : $m(c)$ refers to the average of native Chinese speakers' contextual appropriateness assessment on the speech acts of criticism produced by native American speakers; m(a) refers to the average of native American speakers' contextual appropriateness assessment on their speech acts of criticism; $\mathrm{m}(\mathrm{lcl})$ refers to the average of the lower proficiency Chinese English learners' contextual appropriateness assessment on native American speakers' speech acts of criticism; $\mathrm{m}(\mathrm{hcl})$ ) refers to the average of the higher proficiency Chinese English learners' contextual appropriateness assessment on native American speakers' speech acts of criticism.

5.2 The Influence of L2 Proficiency on Pragmatic Transfer in Perception of Criticisms 
As shown above, pragmatic transfer occurs at the level of perception. This section makes an analysis of the influence of L2 proficiency on pragmatic transfer in 11 of the 12 speech acts of criticism under research where pragmatic transfer occurs at the level of perception.

On 2 of the speech acts of criticism produced by NAES, the average of LCEL' contextual appropriateness assessment is smaller than that of ICEL's which is bigger than that of HCEL's. So, we can see that from LCEL to ICEL, the relationship between L2 proficiency and pragmatic transfer is negative, that is, the degree of pragmatic transfer decreases when L2 proficiency improves; that from ICEL to HCEL, the relationship is positive, that is, the degree of pragmatic transfer turns to increase when L2 proficiency further improves; and that the relationship, in general, belongs to U type.

On 4 of the speech acts of criticism produced by NAES, the average of LCEL' contextual appropriateness assessment is smaller than that of ICEL's which is also smaller than that of HCEL's. From LCEL to ICEL, and to HCEL, the degree of pragmatic transfer reduces when L2 proficiency increases, and the relationship between L2 proficiency and pragmatic transfer is negative, which belongs to straight descending type.

On 4 of the other speech acts of criticism produced by NAES, the average of LCEL' contextual appropriateness assessment is bigger than that of ICEL's which is smaller than that of HCEL's. So, from LCEL to ICEL, the relationship between L2 proficiency and pragmatic transfer is positive - the degree of pragmatic transfer increases with the increase of L2 proficiency, and from ICEL to HCEL, the relationship is negative - the degree of pragmatic transfer decrease when L2 proficiency further improves. Seen as a whole, the relationship belongs to inverted U type.

On 1 of the speech acts of criticism produced by NAES, the average of LCEL' contextual appropriateness assessment is bigger than that of ICEL's which is also bigger than that of HCEL's. So, from LCEL to ICEL, and to HCEL, the degree of pragmatic transfer increases with the increase of L2 proficiency, and the relationship between L2 proficiency and pragmatic transfer is positive, which belongs to straight ascending type.

The four types of relationship between L2 proficiency and pragmatic transfer - straight ascending type, straight descending type, $U$ type and inverted $U$ type discovered at the level of production - are also found at the level of perception. On a macro level, the relationship is negative, which is consistent with what has been found about the relationship at the level of production. In 11 of the speech acts of criticism under research, the relationship of straight ascending type is presented only in 1 of them, while the relationship of straight descending type (4) and inverted type (4) takes about $72 \%$ of all the 4 types of relationship.

Table 4 Types of relationship between L2 proficiency and pragmatic transfer in perception of criticism

\begin{tabular}{|c|c|c|c|c|}
\hline $\begin{array}{l}\text { Speech acts } \\
\text { of criticism }\end{array}$ & $\begin{array}{l}\text { Straight } \\
\text { ascending }\end{array}$ & $\begin{array}{l}\text { Straight } \\
\text { descending }\end{array}$ & $\mathbf{U}$ & Inverted $\mathbf{U}$ \\
\hline 1 & & & $\sqrt{ }$ & \\
\hline 2 & & $\sqrt{ }$ & & \\
\hline 3 & \multicolumn{4}{|c|}{ Where pragmatic transfer does not occur. } \\
\hline 4 & & & & $\sqrt{ }$ \\
\hline 5 & & $\sqrt{ }$ & & \\
\hline 6 & & & & $\sqrt{ }$ \\
\hline 7 & & $\sqrt{ }$ & & \\
\hline 8 & & & $\sqrt{ }$ & \\
\hline 9 & & & & $\sqrt{ }$ \\
\hline 10 & $\sqrt{ }$ & & & \\
\hline 11 & & $\sqrt{ }$ & & \\
\hline 12 & & & & $\sqrt{ }$ \\
\hline
\end{tabular}

\section{Conclusion}

The present study analyzes the relationship between L2 proficiency and pragmatic transfer according to the judging criteria at both levels of production and perception. Findings of the study prove that L2 proficiency does influence pragmatic transfer: the relationship is not merely positive, neither simply negative, but varies with different semantic formulas or modifiers, presented in four types - straight ascending type, straight descending type, $\mathrm{U}$ type and inverted $\mathrm{U}$ type. 
Although, in general, the degree of pragmatic transfer decreases as L2 proficiency increases at both levels of production and perception, there is some discrepancy in use frequency of the speech act of criticism, its semantic formulas and modifiers even between high proficiency Chinese English learners and native American English speakers. This fact reminds us that there is much room even for HCEL to improve their sociopragmatic knowledge and pragmalinguistic expressive ability about the speech act of criticism, and that it is so difficult and protracted for L2 learners to develop their pragmatic competence. Therefore, in classroom teaching foreign language teachers should not only impart linguistic knowledge to learners and cultivate their basic language skills, but also expound pragmalinguistic and sociopragmatic knowledge of the target language by means of overt teaching methods. When a certain speech act in the target language is taught, L2 learners should not only master the linguistic forms of realizing the speech act, but also know its sociopragmatic norms, standards and principles as well as the optimal choice in different contexts.

The study is supported by "the Fundamental Research Funds for the Central Universities" (3142018060).

\section{References}

Bardovi-Harlig, K. \& Hartford, B. S. (1993). Refining the DCT: Comparing open questionnaires and dialogue completion tasks. In L. Bouton \& Y. Kachru (Eds.), Pragmatics and Language Learning 4. Urbana, IL: University of Illinois at Urbana-Champaign.

Blum-Kulka, S. (1982). Learning to say what you mean in a second language: a study of the speech act performance of learners of Hebrew as a second language. Applied Linguistics, (3): 29-59.

Blum-Kulka, S. (1987). Indirectness and politeness in requests: Same or different? . Journal of Pragmatics, (11): $131-146$.

Clark, H. (1979). Responding to indirect speech acts. Cognitive Psychology, (11): 430-477.

Lu Jiawei. (2010). A Review of Studies on Pragmatic Transfer. Journal of Ocean University of China (Social Sciences Edition), (2): 101-105.

Hoa, Hoang Thi Xuan. (2007). Criticizing behavior by the Vietnamese and the American: topics, sodial factors and frequency. VNU Journal of Science, Foreign Languages, (23): 141-154.

Kasper, G. (1992). Pragmatic transfer. Second Language Research, (8) : 203 231.

Maeshiba, N., Yoshinaga, N., Kasper, G. \& Ross, S. (1996). Transfer and proficiency in interlanguage pragmatics. In S. Gass \& J. Neu (Eds.), Speech acts across cultures. Berlin: Mouton de Gruyter.

Nguyen, Thi Thuy Minh. (2005). Criticizing and Responding to Criticism in a Foreign Language: a Study of Vietnamese Learners of English. University of Auckland.

Takahashi, S. (1996). Pragmatic transferability. Studies in Second Language Acquisition, (18): 189-223.

Tracy, K., Van Dusen, D. \& Robinson, S. (1987). Good and bad criticism: a descriptive analysis. Journal of Communication, (37): 46-59.

Wierzbicka, A. (1985). Different cultures, different languages, different speech acts. Journal of Pragmatics, (9): 145- 161.

Wierzbicka, A. (1987). English Speech Act Verbs: A Semantic Dictionary. Marrickville: Academic Press Australia. 